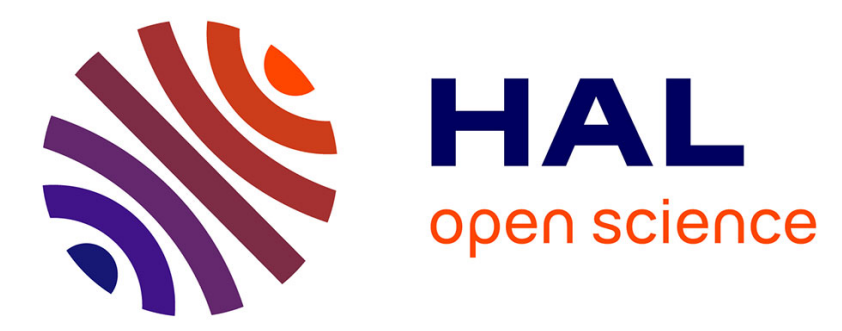

\title{
Precipitation, soil moisture and runoff variability in a small river catchment (Ardèche, France) during HyMeX Special Observation Period 1
}

J. Huza, A.J. Teuling, Isabelle Braud, J. Grazioli, L.A. Melsen, G. Nord, T.H. Raupch, R. Uijlenhoet

\section{To cite this version:}

J. Huza, A.J. Teuling, Isabelle Braud, J. Grazioli, L.A. Melsen, et al.. Precipitation, soil moisture and runoff variability in a small river catchment (Ardèche, France) during HyMeX Special Observation Period 1. Journal of Hydrology, 2014, 516, p. 330 - p. 342. 10.1016/j.jhydrol.2014.01.041 . hal01068013

\section{HAL Id: hal-01068013 https://hal.science/hal-01068013}

Submitted on 24 Sep 2014

HAL is a multi-disciplinary open access archive for the deposit and dissemination of scientific research documents, whether they are published or not. The documents may come from teaching and research institutions in France or abroad, or from public or private research centers.
L'archive ouverte pluridisciplinaire HAL, est destinée au dépôt et à la diffusion de documents scientifiques de niveau recherche, publiés ou non, émanant des établissements d'enseignement et de recherche français ou étrangers, des laboratoires publics ou privés. 


\title{
Precipitation, soil moisture and runoff
}

\author{
variability in a small river catchment
}

(Ardèche, France) during HyMeX Special

\section{Observation Period 1}

Jessica Huza ${ }^{(1,2,5)}$, Adriaan J. Teuling ${ }^{(1)}$, Isabelle Braud ${ }^{(2)}$, Jacopo Grazioli ${ }^{(4)}$, Lieke A. Melsen ${ }^{(1)}$, Guillaume $\operatorname{Nord}^{(3)}$, Timothy H. Raupach ${ }^{(4)}$ Remko Uijlenhoet $^{(1)}$

January 22, 2014

1. Hydrology and Quantitative Water Management Group, Wageningen University, Wageningen, The Netherlands

2. UR HHLY, Hydrology-Hydraulics, Irstea, Villeurbanne, France

3. Laboratoire d'étude des Transferts en Hydrologie et Environnement, Grenoble, France 
4. Environmental Remote Sensing Laboratory, École Polytechnique Fédérale de Lausanne, Lausanne, Switzerland

5. Water Department, Environment \& Infrastructure, AMEC Americas, Montréal, Canada 


\begin{abstract}
Flash flooding is a potentially destructive natural hazard known to occur in the Cévennes-Vivarais region in southern France. HyMeX (Hydrological Cycle in the Mediterranean Experiment) is an international program focused on understanding the hydrological cycle in the Mediterranean basin. Soil moisture is known to be a useful indicator of catchment response, however, establishing a meaningful estimation of soil moisture at the catchment level can be difficult due to its high variability in space and time.
\end{abstract}

In a small gauged catchment in the Cévennes-Vivarais region in southern France, a series of manual soil moisture measurements was taken from September to December 2012 at both the field and catchment scale during the Special Observation Period 1 (SOP1) as part of the HyMeX program. Six plots were selected along a trajectory of a microwave link installed in the catchment and were chosen to represent different elevations in the catchment. Within each field plot, surface soil moisture was measured along a $50 \mathrm{~m}$ transect at $2 \mathrm{~m}$ intervals. This allowed the study of changes in within-field variability as well as between-field variability in response to precipitation events and during the drying out phase.

Several precipitation events occurred over this autumn 2012 period which caused a significant wetting-up of the catchment, allow- 
ing the study of soil moisture processes over a wide range of wetness conditions. The influence of antecedent catchment conditions (soil moisture) on rainfall-runoff dynamics is demonstrated through the comparison of storm hydrographs for the various events. Dry catchment conditions result in minimal response in event flow, whereas large precipitation events occurring during wetter conditions produce much stronger responses in event flow. This further confirms the importance of quantifying catchment initial conditions to enhance the prediction of flash flood occurrences.

Keywords: initial soil moisture, small catchments, HyMeX, runoff generation, temporal stability, soil moisture spatial variability 


\section{${ }_{34} 1$ Introduction}

44 ing heavy precipitation and flash flooding.

47 periods (Drobinski et al., 2013). Typical to this highly variable hydrologi-

48 cal cycle is the occurrence of heavy precipitation causing flash flooding and

49 floods (Gaume et al., 2004; Delrieu et al., 2005; Borga et al., 2007; Gaume

50 et al., 2009). The FloodScale project, which is centered around the Cévennes-

${ }_{51}$ Vivarais region in southern France, contributes to the HYMEX initiative and

52 aims to deepen the understanding of flash flood occurrences and the con-

53 tributing hydrological processes. 
Soil moisture conditions are of particular importance for predicting hydrological processes because they can influence the relative proportion of rainfall

input among the possible overland and subsurface pathways (Massari et al., 2013). Root zone soil moisture has been shown to influence the dynamics of evapotranspiration and drainage processes (Albertson and Kiely, 2000) leading to impacts on the partitioning of latent and sensible heat exchanges to the atmosphere. Furthermore, the antecedent soil moisture conditions of a catchment have been shown in previous studies to be very influential in predicting flood occurrence (De Michele and Salvadori, 2002; Norbiato et al., 2009; Sangati et al., 2009; Tramblay et al., 2010), also specific for Mediterranean regions (Massari et al., 2013; Aronica and Candela, 2004).

\section{(1)} Obtaining representative catchment scale soil moisture measurements, even in small catchments, can be difficult given the dynamic spatial and temporal behaviour of soil moisture (Teuling and Troch, 2005; Brocca et al., 2009a). Previous studies have shown the influence of topographical features (Famiglietti et al., 1998; Brocca et al., 2007) and soil properties (Teuling and Troch, 2005) on soil moisture values found at the field scale. In a theoretical study done by Albertson and Montaldo (2003), the temporal dynamics of soil moisture were explored in the context of the relative influences of parameters 
such as soil, vegetation, precipitation, topography, and initial soil moisture.

All parameters were shown to influence the temporal and spatial dynamics of soil moisture, proving that obtaining accurate soil moisture conditions at the catchment scale for use in flood prediction can be difficult.

Despite soil moisture being highly variable at small scales, soil moisture fields have been known to display temporal stability. This concept was first introduced by Vachaud et al. (1985) who noticed that, although soil moisture variability can be quite high, deviations from the spatial mean show a strong temporal persistence. Chen (2006) introduced the term rank stability to describe the temporal stability of soil moisture. In a review on soil moisture observation studies, Vanderlinden et al. (2012) show that rank stability in soil moisture has been observed under a wide range of conditions; at different spatial scales, different temporal scales, and for different soil and vegetation types, although Martínez et al. (2013) showed that a relation exists between rank stability and climate and soil properties. From this concept, it follows that a limited number of point measurements might be sufficient to infer areal or catchment mean values for soil moisture (Teuling et al., 2006; Brocca et al., 2012). In addition to in-situ measurements, which are accurate but mainly ap- 
plicable at smaller scales (Brocca et al., 2013), remote sensing data are an important source to map large scale soil moisture fields. This is achieved through various widely used satellite products, such as Advanced SCATterometer, ASCAT (Bartalis et al., 2007), the Soil Moisture and Ocean Salinity Satellite SMOS (Kerr, 2007), Advanced Microwave Scanning Radiometer for Earth observation, AMSR-E (Owe et al., 2008), and the Microwave Imaging Radiometer with Aperture Synthesis, MIRAS (Kerr et al., 2010). The soil moisture data obtained through these sensors are applied in the field of hydrology for multiple purposes including but not limited to weather analyses and forecasting. Since remote sensing soil moisture products are still under development (see e.g. Wagner et al. (2013)), ground measurements are of high importance for the validation of remote sensing products (Cosh et al., 2004).

In order to improve the understanding of the rainfall-runoff dynamics of small Mediterranean catchments, a field measurement campaign was set up during the HyMeX Special Observation Period (SOP1), which spans from the period of 14 September 2012 to 5 December 2012. SOP1 is a short period spanning the seasonal scale where an increased number of hydrological observations occur in specific catchments. During this period, in situ soil moisture measurements were conducted in a structured way at various scales. These 
data have been compared to precipitation data from several sources, and soil moisture satellite data. This study has the following research objectives; (i) quantify the temporal and spatial soil moisture variability at the field (or transect) scale and catchment scale; (ii) determine whether regional-scale soil moisture measurements can be used for prediction of field-scale hydrological processes; (iii) study the influence of spatio-temporal variability of precipitation on that of soil moisture; (iv) quantify the relationship between catchment initial conditions (soil moisture) and runoff processes.

First, the research area and the field work strategy will be described, followed by a presentation of the results obtained through the collection of environmental data. Finally a discussion of the results, along with some perspectives will be given.

\section{Data and methods}

\subsection{Gazel Catchment}

The study site is located in the Ardèche catchment, as seen in Figure 1, which is a mesocale catchment of $2,350 \mathrm{~km}^{2}$. In the north eastern part of this catchment two smaller nested sub-catchments are located; the Claduègne and the Gazel, which are $43 \mathrm{~km}^{2}$ and $3.4 \mathrm{~km}^{2}$ in areas respectively. The field 
experiments for soil moisture measurements were carried out during the fall 2012 SOP1 in the Gazel, a small sub-catchment of the Ardèche with an area of $3.4 \mathrm{~km}^{2}$ (Figure 1). The Gazel catchment is characterized by a steep south facing slope in the northern part that becomes more gradual near the southern part of the catchment. The elevation of the upper part of the catchment is roughly $630 \mathrm{~m}$, while the elevation at the catchment outlet is approximately $270 \mathrm{~m}$. The upper part of the catchment is characterized by basalt formations, after which a sharp transition occurs where the lower two thirds is made up of sedimentary limestone rock. The soil types are heavily influenced by the geology of the catchment. Volcanic soils and silty-sandy soils are found in the upper and lower part of the catchment, respectively. In addition, proportions of clay are also found in the soils (see Table 1), and the main land use type is pastures and vineyards. Average annual precipitation is approximately $1030 \mathrm{~mm}$ (based on daily rain gauge data operated by MéteoFrance located at Le Pradel (Figure 1) in the catchment for the period of 1958-2000).

\subsection{Precipitation}

Precipitation data were received from the following sources: radar data from the X-band dual polarization weather radar (spatial and temporal resolution 
of $75 \mathrm{~m}$ and 3 minutes, respectively) located approximately $5 \mathrm{~km}$ north east of the Gazel catchment, rain gauges and disdrometers located in the upper and lower part of the catchment, and a microwave link running in a north-south direction (Figure 1). The rain gauge and disdrometer data were received for the whole period that soil moisture measurements were done. For the rain gauge located in the village of Mirabel (upper part of the catchment), only data up to 27 October 2012 were available due to technical issues that persisted until after the field work was completed.

Hourly precipitation sums were computed for both the radar and the disdrometer data. In addition, each soil moisture measurement was attributed a precipitation sum, which was calculated by totalling all rainfall occurring during the interval of the previous and current soil moisture measurement. For soil moisture measurements occurring on non-consecutive days, a maximum of three days leading up to the soil moisture measurement was used as the interval length for accumulating rainfall depth.

\subsection{Soil moisture data}

To evaluate the soil moisture spatial and temporal dynamics, a sampling strategy was designed that allowed for capturing both soil moisture condi- 
tions at the catchment scale as well as the field-scale with a single handheld instrument. Point volumetric soil moisture measurements were done using a portable three-prong (6 cm rod length) ThetaProbe unit (Delta-T Devices Ltd, Cambridge, UK), which employs the time domain reflectometry (TDR) technique. The uncertainty in limiting measurements to the top $6 \mathrm{~cm}$ were compared through side-by-side measurements of five transects with an additional TRIME-PICO 64 TDR-probe (IMKO GmbH, Ettlingen, DE) having a rod length of $16 \mathrm{~cm}$. In Figure 2, it can be seen that the two sensors agree quite well based on the small differences between the sensors. The $6 \mathrm{~cm}$ ThetaProbe was chosen for the field measurements because of increasing stoniness with depth found in many fields, which complicated the use of the TDR with longer rod length.

Fields were selected to appropriately represent the catchment, while still capturing inter-field variability and the influence of different topographical features. The criteria in selecting the location of the different fields throughout the catchment were the following: two fields should be chosen to be in close proximity of the rain gauge and disdrometers found at the Le Pradel and Mirabel sites (blue arrows in Figure 1). The fields in between should be selected in a way that they are aligned with the path of the microwave link, and be equally spaced between to account for the variation of altitude 
in the catchment (increasing towards the north). The following factors were taken into consideration when selecting the fields: ability to measure, ease of access, and reduced interference (such as ploughing or tilling of the field). Vineyards were not selected because the soil was dominated by stones, making it impossible to sample without breaking the sensor. This resulted in all selected fields being pastures and grasslands (see Table 1 for a full description of the fields selected).

Within each of the selected six fields, a transect path of $50 \mathrm{~m}$ was measured. The location of the transect within the field was chosen in order to capture the spatial heterogeneity of the field. If possible, the transect location within the field was selected to align with the path of the microwave link. Along the $50 \mathrm{~m}$ transects, a measurement was taken at spatial intervals of $2 \mathrm{~m}$ and all measurements were done at the same location for each of the measurement days. On each measurement day, all fields were measured within a few hours to minimize the influence of evaporation and drainage processes. The strategy was to select measurements days that aligned with high precipitation events and to capture both pre-event and post-event soil moisture conditions whenever possible. Between the period of 14 September 2012 to 5 December 2012, 16 measurement days were completed on the six different transects. This produced approximately 2,500 soil moisture measurements. 
In addition to soil moisture field data, satellite soil moisture data from the Advanced Scatterometer (ASCAT) on the meteorological operational (MetOp) platform sensor (Figa-Saldaña et al., 2002) were downloaded from http://www.esa-soilmoisture-cci.org. This data is downloaded using the TUWien algorithm, more information regarding the algorithm can be found in Wagner et al. (1999) and Naemi et al. (2009). The coarse spatial (between 25-50 km) and temporal resolution (revisit time of 1 day or less over Europe) of this data, as well as its high measurement uncertainties make it a challenge to validate in situ data. The reliability of soil moisture estimates from remote sensing data remains a challenge that Brocca et al. (2011) have recently addressed. Correlation coefficients with observed soil moisture data ranging from 0.71 to 0.81 , depending on scaling methods, were obtained for the ASCAT sensor over different regions in Europe. The remote sensing data were used for the period of 1 September 2012 to 29 November 2012, and was rescaled as the output provided by the ASCAT sensor is not volumetric soil moisture $\theta_{v}$. 


\subsection{Soil moisture analysis}

This work includes the study of the temporal and spatial aspects of the volumetric soil moisture field $\theta(x, t)$ as vol $\%$, where both $x$ and $t$ denote the spatial and temporal components of the observations. The subscript $i$ is used to represent a discrete measurement point in space along a transect up to $n=26$ measurements, and the subscript $j$ is used to distinguish between the different fields being sampled (Transect A through F) up to $m=6$ fields $\left(x_{i, j}=\left\{x_{A, 1}, \ldots, x_{m, n}\right\}\right)$.

Each soil moisture measurement day is defined as $t_{d}=\left\{t_{1}, t_{2}, \ldots, t_{k}\right\}$ where $d$ refers to the measurement day, with the number of total days being equal to $k=16$. The volumetric soil moisture at a discrete point along a transect is denoted by $\theta\left(x_{i, j}, t_{d}\right)$, and $\bar{\theta}\left(x_{j}, t_{d}\right)$ represents the daily transect mean for a particular field. The daily catchment mean will be denoted as $\bar{\theta}_{d}$.

For each measurement day $d$, the mean for each of the $m$ fields is computed $\bar{\theta}\left(x_{j}, t_{d}\right)$ as well as the daily catchment mean $\bar{\theta}_{d}$ :

$$
\bar{\theta}\left(x_{j}, t_{d}\right)=\frac{1}{n} \sum_{i=1}^{n} \theta\left(x_{i, j}, t_{d}\right)
$$

249

$$
\bar{\theta}_{d}=\frac{1}{m} \sum_{j=1}^{m} \bar{\theta}\left(x_{j}, t_{d}\right) .
$$


253

The standard deviation of the soil moisture observations within the transect $s\left(\theta\left(x_{j}, t_{d}\right)\right)$ and the standard deviation of the means among the different transects $s\left(\theta_{d}\right)$ is estimated by:

$$
s\left(\theta\left(x_{j}, t_{d}\right)\right)=\sqrt{\frac{1}{n-1} \sum_{i=1}^{n}\left(\theta\left(x_{i, j}, t_{d}\right)-\bar{\theta}\left(x_{j}, t_{d}\right)\right)^{2}},
$$

$$
s\left(\theta_{d}\right)=\sqrt{\frac{1}{m-1} \sum_{x=1}^{m}\left(\bar{\theta}\left(x_{j}, t_{d}\right)-\bar{\theta}_{d}\right)^{2}} .
$$

Using these equations, the relationship between mean soil moisture and its standard deviation can be studied at both the transect scale and the catchment scale.

The mean soil moisture of a transect at a specific time $t$ is estimated through $n$ discrete observations, and the uncertainty of this estimate will decrease as the number of observations increases. The uncertainty of the transect mean can be computed through calculating the standard error of the mean. The validity of this equation applies to spatially uncorrelated observations. Additional measurements were performed during this field work at a scale smaller than $2 \mathrm{~m}$, in which distances ranging from $1 \mathrm{~cm}$ up to $2.8 \mathrm{~m}$ were measured. Large spatial variability was observed at scales much smaller than $2 \mathrm{~m}$, based on a geostatistical analysis of the data. This implies that the discrete measurements at $2 \mathrm{~m}$ intervals along the transect can indeed be 
272

assumed to be spatially independent, which further allows for the application of this equation. The standard error $(S E)$ of the transect mean volumetric soil moisture $\theta\left(x_{j}, t_{d}\right)$ in this example is given by:

$$
S E=\frac{s\left(\theta\left(x_{j}, t_{d}\right)\right)}{\sqrt{n}}
$$

Furthermore, the different transects measured can be evaluated in terms of temporal stability. The spatial difference $\delta_{j, d}$ is defined as the difference between the soil moisture transect mean $\bar{\theta}\left(x_{j}, t_{d}\right)$ and the catchment mean $\bar{\theta}_{d}$ such that:

$$
\delta_{j, d}=\bar{\theta}\left(x_{j}, t_{d}\right)-\bar{\theta}_{d}
$$

The temporal mean difference $\bar{\delta}_{j}$ for every site is then estimated as:

$$
\bar{\delta}_{j}=\frac{1}{k} \sum_{d=1}^{k} \delta_{j, d}
$$

In order to rank the fields to determine which field is the most stable site in time, the field with the smallest temporal mean difference will be considered as the field that on average best represents the catchment mean soil moisture on a given day. The variability of the temporal mean difference for each field $s\left(\delta_{j}\right)$ can be computed as:

$$
s\left(\delta_{j}\right)=\sqrt{\frac{1}{k-1} \sum_{d=1}^{k}\left(\left(\delta_{j, d}\right)-\bar{\delta}_{j}\right)^{2}} .
$$




\subsection{Discharge}

At the catchment outlet of the Gazel, the water depth is logged every second and averaged over two minute intervals. This depth is converted into a discharge measurement through a stage-discharge relationship. An optimal stage-discharge relationship is provided through the Baratin tool ( Le Coz et al., 2013), and subsequent minimum and maximum stage-discharge curves are derived as the 5\% and 95\% statistical distribution based on Monte Carlo simulations. The difference between the maximum and minimum discharge is used to estimate the error of the discharge measurement.

The discharge data was aggregated to hourly averages over the period of the field work campaign. To investigate the influence of soil moisture on runoff processes, the hydrograph of selected storm events were analysed.

The baseflow was removed through a baseflow separation technique where a minimum flow of 5 consecutive days is computed and turning points are identified. For more details on this technique readers are referred to Tallaksen and Van Lanen (2004). To further analyse the hydrograph and to allow for comparison between the events, the runoff ratio (RR) was calculated by dividing the cumulative event discharge by the cumulative precipitation for a particular event. 


\section{Results}

\subsection{Precipitation}

Precipitation was measured with two disdrometers located in the catchment at a temporal resolution of 30 seconds (blue arrows in Figure 1). An average of the two disdrometers was used to provide a daily catchment mean over the observation period (upper panel of Figure 3). Four events of significant precipitation occurred throughout the SOP1, in which soil moisture measurements are clustered around days that coincide with these strong precipitation events. Throughout the SOP1, approximately $279 \mathrm{~mm}$ of rain was recorded by the two disdrometers located in the catchment, as compared to $333 \mathrm{~mm}$ as recorded by the co-located rain gauges. The rainfall estimates throughout the period for the lower part of the catchment were $288 \mathrm{~mm}$ and $333 \mathrm{~mm}$ for the disdrometer and rain gauge, respectively. For the upper part of the catchment, the disdrometer recorded $269 \mathrm{~mm}$ over the same period. Technical problems occurred at the rain gauge located in the upper part of the catchment, resulting in only the rain gauge located in the lower part of the catchment recording precipitation beyond 27 October 2012. For daily 
intensities recorded throughout SOP1 were $53 \mathrm{~mm} \mathrm{day}^{-1}$ and $57 \mathrm{~mm} \mathrm{day}^{-1}$ for the disdrometer and rain gauges respectively, both recorded in the lower part of the catchment. If the total precipitation sums as recorded by both the disdrometer and the rain gauges are compared for the four periods where soil moisture measurements were done (see section 3.3), it can be seen that the disdrometer consistently records about $22 \%$ less precipitation than the rain gauges. Without having rain gauge data available in the upper part of the catchment for the full observation period, it is unclear if this difference is due to spatial variability of precipitation or related to the measurement technique itself.

The precipitation characteristics of five events are compared in Table 2. Looking at the standard deviation $\operatorname{sd}(P)$ and coefficient of variation $\mathrm{CV}(P)$ of the hourly precipitation measured in the lower and upper part of the catchment, it can be seen that the variability was significantly higher within the catchment in the Event \#1 as compared to the other events. More details of this first event can be found in Table 2, where the total precipitation accumulated over the event period was computed for the upper and lower part of the catchment through the following four techniques (Table 2): Rain gauges, disdrometers, X-band dual polarization weather radar, and microwave link (provides a single path-averaged value along the trajectory of the link). Due 
to the occurrence of hail in the upper part of the catchment, the ice phase precipitation was removed from the total measured precipitation by the disdrometer near Transect $\mathrm{E}$ as seen in Table 3. It can be seen that the different measurement techniques produce a range of precipitation accumulation values, with the highest recorded by the rain gauges $(24 \mathrm{~mm})$ and the lowest by the radar $(17 \mathrm{~mm})$. This highlights the challenge in obtaining accurate precipitation measurements.

\subsection{Soil moisture}

\subsubsection{Temporal evolution during SOP1}

A wide range of soil moisture conditions was captured during the SOP1, as can be seen in the lower panel of Figure 3. Soil moisture measurements are indicated by the points in the lower panel, the error bars provide information related to the range seen at the individual transects (recall that the catchment mean is an average of the six individual transect fields). At the beginning, very dry conditions are measured with a soil moisture mean of 12.5 vol \% first recorded in mid-September. However, by the end of the observation period the catchment has become significantly wetter with a catchment mean soil moisture of $31.9 \mathrm{vol} \%$. A maximum mean soil moisture is seen near the end of November, after the occurrence of a significant rainfall event, for which 
the catchment mean of 38.5 vol \% was measured.

The difference among the six transects, as shown by the error bars in the lower panel of Figure 3, can be seen to be quite small at the beginning of the observation period when conditions are dry. The size of the error bars increases along with increasing soil moisture. Details on the soil moisture values obtained at the transect scale can be found in Table 1.

\subsubsection{Temporal variability: catchment and field scale}

Soil moisture shows a large temporal variability during the dry-wet transition of SOP1, covering a large soil moisture range. Initial values at the end of summer were close to wilting point, and approached field capacity after repeated precipitation events (Figure 3). In addition, there was also a large variability of the mean soil moisture between the different transects throughout the SOP. Approximate 95\% confidence intervals for the transect means are shown in Figure 5, calculated as two times the standard error assuming spatially independent observations (based on the geostatisical analysis described in section 3.2.3). Overlapping error bars imply that two transect means may not statistically different. This assumption was further tested with the post hoc Tukey Honestly Significant Difference test (interested readers are referred 
to Salkind (2010)). The Tukey HSD test confirmed the results obtained from comparing the transect means based on overlapping error bars. Visual inspection shows that on DOY 267, 270, and 334, the variability between the different field means is quite low with all transect means having overlapping error bars. This provides an indication of the variability throughout the catchment as being small on those particular days. Interestingly enough, a wide range of soil moisture conditions are seen on those days, with this behaviour occurring in both dry, mid-range, and wet conditions. The length of the error bars on these days provides insight into the variability within the transect. The signal is slightly different at this smaller scale. On DOY 267, the error bar length of all transects is quite small, with DOY 270 and 334 displaying longer error bars, indicating more variability within the field. It can be concluded that by sampling in a randomly selected field only, the resulting field-scale soil moisture dynamics will not be representative for the catchment scale mean.

\subsubsection{Spatial variability: catchment and field scale}

The relation between soil moisture variability and mean soil moisture at the catchment and field scale is shown in Figure 6, where standard deviations within-field and between-field along with soil moisture conditions are plotted separately. Both plots are fitted with a linear regression line along with the 
95\% confidence interval lines. A better fit is seen for the between-field variability than within-field, as reflected by many more points falling outside the confidence lines in the former than in the latter. However, it should be noted that given a limited number of fields (6), the between-field variability cannot be confidently implied through the computation of the standard deviation. Nonetheless, using standard deviation as a measure of between-field variability can still serve to compare between-field variability among the different measurement days. During dry conditions, both variabilities show a small standard deviation of approximately $2 \mathrm{vol} \%$. In humid conditions, betweenfield variability increases to approximately 3.5 vol $\%$ as the soil moisture mean approaches $40 \mathrm{vol} \%$. Within-field variability can be anywhere from $2.5 \mathrm{vol} \%$ to $7 \mathrm{vol} \%$, with a maximum seen in very wet conditions of $8 \mathrm{vol} \%$.

Although within-field variability exceeded between-field variability, some evidence was found for the impact of landscape-scale controls on soil moisture variability. To explore the existence of spatial structure at the transect scale and the influence of topography (see Table 1 for differences in slope among the transects), two empirical semivariograms (Goovaerts, 1997) were computed for Transects A and F (Figure 7). The first semivariogram was based on 101 randomly spaced points ranging from $1 \mathrm{~cm}$ to $2.8 \mathrm{~m}$ (upper panel of Figure 7), as well as using all measurements collected throughout 
the observation period at $2 \mathrm{~m}$ intervals (lower panel of Figure 7). Note that Transect A and F represent end-members for slope and elevation in the Gazel catchment. The standard deviations are plotted as error bars and based on the approach shown in the upper panel (101 randomly spaced points), Transect $\mathrm{A}$ shows a larger variability. However, when all points at $2 \mathrm{~m}$ spacing are averaged out for Transect A and F, the latter transect shows a significantly greater variability as evidenced by the longer error bars. Large variability is seen at small scales as evidenced by the large nugget in both transects. In the lower panel, a difference among the transects is seen, with evidence of a sill in Transect F that is not apparent in Transect A.

\subsubsection{Temporal stability of the transects}

In Figure 8, the transects have been sorted based on their mean difference with respect to the spatial mean $\bar{\delta}_{j}$ in order to investigate the temporal or rank stability of soil moisture in the Gazel catchment. Teuling et al. (2006) showed that on individual dates the site that on average best represents the catchment has a low probability of being identified. For that reason, to identify the site that on average best represents the catchment mean, the average of the spatial means computed for each of the observation days is taken. Temporal variability, defined as the standard deviation of the spatial 
mean difference $s\left(\bar{\delta}_{j}\right)$, is plotted as error bars. The transect with $\bar{\delta}_{j}$ closest to zero can be termed as the most rank stable site, and is best for representing the catchment mean.

Transect D was found to exhibit the highest rank stability. Not only does this field have the smallest mean difference with respect to the spatial mean, but the variability of this difference on any day was smallest, making this transect likely to be selected based on limited sampling.

\subsubsection{Precipitation-induced spatial variability}

To further investigate the occurrence of large differences among the transect means (Figure 5), including what hydrological processes may have contributed to these differences, the mean soil moisture observations on DOY 267 and 268 (Event \#1) are investigated in more detail along with the precipitation data. On DOY 267 (23 $3^{\text {rd }}$ September 2012), Transects A and E had very similar transect mean soil moisture values (14.8 vol \% and 14.2 vol \% respectively). However, the following day a large scatter in the field means occurred where Transect A increased up to 32 vol \% whereas Transect E increased only up to 23.9 vol \%. This implies a difference in volumetric soil moisture of $8.1 \mathrm{vol} \%$ between the fields. 
Looking at the precipitation data, it can be seen that disdrometer, rain gauge, and radar data (microwave data excluded due to only a single pathaveraged estimate over the link available rather than values at discrete locations in space) all show higher precipitation occurring near Transect A rather than Transect E (Table 3). This analysis shows that the large spatial variability of precipitation was responsible for the creation of variance in the mean soil moisture among the transects over these two observation days.

Precipitation intensity is also relevant to analyse as it can influence soil moisture due to the occurrence of surface runoff from saturation or infiltration excess processes. The disdrometer recorded a maximum precipitation accumulation over a ten minute period of $34 \mathrm{~mm}$ and $21 \mathrm{~mm}$, near Transect A and $\mathrm{E}$, respectively. This is consistent with the accumulated rainfall amounts received in the lower part of the catchment, pointing towards a larger storm occurring at Le Pradel as compared to Mirabel during this time period. $\mathrm{A}$ and $\mathrm{E}$ is computed, the amount of infiltrated precipitation that is being measured in the top $6 \mathrm{~cm}$ on the day after the event can be inferred. Brocca et al. (2013) used soil moisture data to estimate 1 day and 4 day rainfall observations with satisfactory results at the basin level. In this study, a dif- 
ference of $17.2 \mathrm{vol} \%$ (equals $10 \mathrm{~mm}$ of rain) and $9.7 \mathrm{vol} \%$ (6 mm of rain) was computed for the top $6 \mathrm{~cm}$ for Transect A and E, respectively. This preliminary analysis shows that the soil moisture measurements in the top soil only account for approximately half of what was measured as precipitation depth by the precipitation measurement equipment. This further illustrates the fast dynamics of the catchment, and the importance of surface runoff and drainage processes to deeper soil layers in this catchment.

\subsubsection{Comparison between in situ and satellite data}

A time series of the satellite data and the in situ observations over the SOP1 can be seen in Figure 4. The ASCAT output was rescaled with the in situ data through a linear regression using 14 days (Figure 4). A correlation coefficient of 0.55 was obtained through this approach. During some periods throughout the SOP1, there appears to be a small time shift between the two measurements. The time series is plotted on a daily time scale, however some days two measurements were performed followed by none the next day. To avoid gaps in the time series, the second measurement taken in a day was allocated to the following day. This approach could have contributed to the time shift seen between these two data sets. By removing one measurement point where the time difference between the in situ and satellite measurement was 
the greatest, the correlation coefficient of the linear regression increases to 0.74. Despite the time shifts, overall the in situ observations agree well with the remote sensing data. Approximately two-thirds of the in situ measurements fall within the measurement uncertainty band of the ASCAT sensor. The spatial resolutions of the satellite and the in situ observations are quite different, hence it is to be expected that the two measurement types will not agree very well. In addition, satellite observations are representative for the top 2-3 cm, whereas the in situ measurements extend to a depth of $6 \mathrm{~cm}$. Nonetheless, both data sets follow a similar signal, proving that the satellite data can be useful tool to fill in gaps of missing in situ data. This is in line with the results of previous studies on ASCAT soil moisture in France (Albergel et al., 2009). However, it should be noted that replacement of in situ data by satellite data remains a challenge due to the need to calibrate satellite data with in situ data.

\subsection{Runoff response}

Five periods where precipitation occurred during SOP1 are shown in Table 2. Various characteristics are compared for these periods, namely: cumulative precipitation $(P$ sum $)$, standard deviation $(\operatorname{sd}(P))$ and coefficient of variation $(\mathrm{CV}(P))$ between the hourly precipitation in the upper and lower part 
of the catchment, cumulative event flow $\left(Q_{\text {event }}\right.$ sum), runoff ratio $(R R)$, antecedent volumetric soil moisture $\left(\bar{\theta}_{d}\right)$, post-event volumetric soil moisture $\left(\bar{\theta}_{d+1}\right)$, and ASCAT antecedent volumetric soil moisture (ASCAT $\left.\bar{\theta}_{d}\right)$. The base flow has been removed to allow comparison among the different periods. No antecedent or post-event soil moisture are available for Period 5, therefore, Figure 9 shows the hydrographs for the four periods where soil moisture are available.

The first two events (Event \#1 and \#2) show minimal catchment response, with very low cumulative event flow occurring. In both events, the soil moisture increased significantly the day after the storm, showing that the precipitation input served to replenish the soil moisture storage. The influence of a dry catchment on runoff response is particularly interesting in Event \#1, where a significant amount of precipitation fell on the catchment (49 mm), yet hardly any event flow was seen $(0.17 \mathrm{~mm})$. If the subsequent events are explored, the catchment displays an entirely different response. In Event \#3 and \#4, large precipitation amounts occur, resulting in significant rises in event flow. Although no in situ soil moisture measurements were available prior to the last two events, Massari et al. (2013) showed that this can be overcome by using ASCAT satellite data when no in situ soil moisture measurement is available. By comparing satellite antecedent soil 
moisture data with post-event soil moisture, a strong rise following precipitation is seen. By looking at the storm hydrograph, a fast response of event flow to precipitation input during Event \#3 and \#4 occurred, followed by a slow recession in the days after the storm. A similar signal is seen with the soil moisture measurements, in which a gradual decrease occurred after the precipitation event.

The antecedent soil moisture conditions appear to have a large influence on the occurrence of runoff processes in this catchment. This relationship was further investigated by analysing the runoff ratio for the five precipitation events shown in Table 2. In Figure 10a, the different runoff ratios are plotted against their corresponding re-scaled initial soil moisture from the ASCAT satellite sensor. The error bars for the runoff ratios are based on the error of the discharge as calculated through the difference between the minimum and maximum stage-discharge curves. The error bars for the re-scaled ASCAT initial soil moisture represent the re-scaled measurement error from the satellite. A generally increasing trend is seen where small runoff ratios occur for dry catchment conditions, and large runoff ratios correspond to wetter conditions. It can also be seen that small events are shown to result in very low runoff ratios during both dry and wet conditions. A strongly nonlinear relationship between (soil moisture) storage and runoff behaviour 
can be hypothesized.

The event flow rate at the time of soil moisture measurements is also examined in Figure 10b. The error bars indicate the maximum and minimum event flow rates (baseflow removed) due to the uncertainty in the stagedischarge rating curve (derivation described in Section 2.5). The event flow is shown to be quite variable for different soil moisture measurements, which indicates that storm size is an important indicator along with catchment initial conditions. Small precipitation events will not induce a strong response in event flow even during wet conditions. However, the catchment will respond strongly to large precipitation events during wet and dry conditions.

\section{Discussion}

\subsection{Methods}

\subsubsection{Soil moisture sensor selection}

The selection of the soil moisture sensor used in the field determines the depth and sampling volume of the soil throughout this study. By using the portable ThetaProbe unit with a rod length of $6 \mathrm{~cm}$, only the top soil was 
measured. By looking at differences in soil moisture from two consecutive measurements days in Table 3, it can be seen that approximately $50 \%$ of the precipitation occurring between two measurements days (DOY 267 and 268) was measured by this sensor in the top $6 \mathrm{~cm}$. Assuming that surface runoff and drainage processes being important in this catchment, the fact that the soil moisture sensor manages to capture such a significant amount of the precipitation further proves the usefulness of the field data for this study.

\subsubsection{Field and transect selection}

The selection of the fields determined the land use type that was measured, which can influence soil moisture observations. In this study only pastures and grasslands were chosen due to the large number of stones found in other land use types which made it impossible to perform field measurements with the probe. Although all land use types are important for runoff generation, vineyards were not considered in this study due to measurement difficulties.

A $50 \mathrm{~m}$ transect within the field was selected to capture the spatial heterogeneity of the field, and was chosen in a way to account for the influence of topographical feature and soil properties on soil moisture. Based on previous studies (Western et al., 1998, 2004), soil moisture spatial patterns were 
found to have correlation lengths between $30-60 \mathrm{~m}$. This suggests that a transect of $50 \mathrm{~m}$ is likely too small to fully capture spatial variation at the field scale. Time constraints required that a single transect per field was measured, as opposed to multiple transects in each field. Therefore, it was necessary that the transect was chosen to account for spatial heterogeneities to best represent the field through a single transect. A spacing of $2 \mathrm{~m}$ was used in this study between discrete measurements along the transect. The influence of this choice was tested by repeating 101 measurements in two different fields, whereby the distances between discrete measurements were as small as $1 \mathrm{~cm}$. No spatial structure was seen on a scale smaller than $2 \mathrm{~m}$ and so it was assumed that the choice of a $2 \mathrm{~m}$ spatial resolution did not significantly impact the study.

\subsection{Temporal variability: catchment and field scale}

A summary of the transect scale volumetric soil moisture can be found in Table 1 (initial, final and maximum volumetric soil moisture is shown), in which the highest soil moisture was measured in Transect F. However, Transect $\mathrm{C}$ was the wettest field measured at the end of the observation period. This transect has the highest clay content (Table 1), and is the only field in 
close proximity to a ditch, where the influence of local groundwater on soil moisture is possible.

\subsection{Spatial variability: catchment and field scale}

The between-field and within-field variance was found to be lower at drier catchment conditions than at wetter conditions (Figure 6), which is contrary to what was reported in recent studies, where a convex upward relationship is becoming more prominent (Famiglietti et al., 2008; Brocca et al., 2010; Rosenbaum et al., 2012; Brocca et al., 2012). This may be due to the high infiltrating soils that characterize this catchment. Drainage processes can contribute to the creation of variance on non-homogeneous soils (Albertson and Montaldo, 2003), which is likely the case in this study due to the high infiltrating soils that would increase the dynamics of this variance creation.

To test the influence of micro-topographical features on the variability within the field, two empirical semivariograms were computed for Transects $\mathrm{A}$ and $\mathrm{F}$ where small scale variability (measurement distances less than $2 \mathrm{~m}$ ) and the variability at the $2 \mathrm{~m}$ interval spacing selected for this study were investigated (Figure 7). A much larger variability is seen in the upper panel 
where 101 randomly spaced points were measured, as opposed to the lower panel, where averages of all measurements at $2 \mathrm{~m}$ spacings throughout the observation period was done. Differences in the semivariograms are seen which may be linked to topography among other factors such as soil properties. In the lower panel, the existence of a spatial structure at point distances greater than $30 \mathrm{~m}$ is seen in the field characterized by a large slope (Transect F). Large nuggets are found in both fields, indicating large variability at small scales. Both findings agree with Brocca et al. (2007), who stated difficulty in identifying a correlation lengths in flat areas.

\subsection{Temporal stability of the transects}

Transect D was shown to be the most rank stable site in the catchment, suggesting that this field would be the optimal site to sample if the catchment mean was to be approximated based on measurements in a single field. Transect $\mathrm{D}$ is characterized by the average topographical properties of all the fields (Table 1) in terms of slope, elevation and soil properties. In addition, this transect is found in the middle part of the catchment suggesting an average value for upslope drainage area. This is consistent with Brocca et al. (2009b), who found that sites which are most representative are "located in 
areas reflecting average topography characteristics, in terms of elevation and slope". This suggests that the best transects for monitoring catchment mean conditions can be selected a priori based on field characteristics.

\subsection{Precipitation-induced spatial variability}

The large local spatial variability of rainfall seen during the event beginning on $23^{\text {rd }}$ September 2012 (Event \#1) is an influencing factor on the variability of the soil moisture mean between the different fields, as evidenced by the large difference in soil moisture measured at Transect A (lower) and E (upper) of the catchment following the event (Table 3). However, this precipitation event was also shown to be characterized by some hail in the upper part of the catchment. The ice phase precipitation was removed from the disdrometer data located in this part of the catchment. The estimate of amount of hail or duration remains difficult making the rain gauge the reference for precipitation (liquid water plus melted solid water) during this event.

\subsubsection{Satellite data instead of in situ data}

Capturing pre-event soil moisture measurements for short-term observation can be a challenge, especially if reliance on accurate weather predictions days 
in advance is required to reach the field site. Long-term options can include the installation of a fixed sensor beneath the soil surface, however, the installation process is intrusive and creates non-natural soil conditions enhancing preferential flow paths. This can lead to inaccurate estimations of catchment scale soil moisture when point measurements are used for upscaling. For a short term observation period, such as in this study, in addition to the desire to measure multiple locations, a portable unit was considered as the optimal solution

The lack of pre-event in situ soil moisture measurements would normally limit the analysis of antecedent soil moisture and catchment response. Given the good agreement between the satellite and in situ soil moisture measured in this study, the gaps in pre-event in situ soil moisture data can be overcome by using satellite data to infer antecedent catchment scale soil moisture.

\subsection{Catchment response to soil moisture}

The effect of antecedent catchment soil moisture conditions on runoff processes was found to be significant in this catchment. By exploring the hydrographs of four selected events during the observation period (Figure 9), a 
link between catchment response and wetness conditions could be made. A comparison between the first two events (Event \#1 and \#2) and the last two events (Event \#3 and \#4) shows strong rises in event flow following precipitation occurring only for Event \#3 and \#4. The runoff ratios for Event \#1 and \#3 show a difference of two orders of magnitude despite only approximately $20 \%$ more precipitation occurring in the latter as compared to the former event. This relatively small difference in precipitation amount as compared to runoff ratio, suggests that the antecedent soil moisture conditions strongly influence in the occurrence of storm runoff. In literature, several studies have shown the relation between antecedent soil moisture and runoff ratio (among others Castillo et al. (2003); Massari et al. (2013)), but also the classical Curve Number method links antecedent soil moisture conditions with the runoff ratio (Ponce and Hawkins, 1996). Massari et al. (2013), who performed a rainfall-runoff modelling study using varying sources of initial soil moisture data, including satellite, in situ, modelled, and constant input data, showed poor model performance when a constant initial soil moisture was used. Norbiato et al. (2009) made a link between larger runoff ratios occurring at higher antecedent soil moisture conditions in catchments characterized by an average sub-surface storage capacity (not an excessively small or large groundwater storage). Both studies show the importance of accurately estimating the initial soil moisture conditions for flood studies. 
The relationship between catchment initial conditions and runoff ratio shows an increasing trend with wetness conditions (Figure 10a), where runoff is likely to occur above approximately $22 \mathrm{vol} \%$. Given that runoff ratio is not a physical quantity in itself, more information regarding the spatial characteristics of precipitation during storm events and pre-event in situ soil moisture observations would be useful to further analyse this hypothesis. In addition, it is important to note that the upper and lower part of the catchment do not respond similarly to precipitation input due to differences in geology. This was reflected in differences in water level observations (not shown).

\section{Conclusion}

In this study, an attempt was made to capture spatial and temporal variability of soil moisture with structured field measurements, and to compare these measurements with different data sources (e.g. precipitation from different sources, and soil moisture products from remote sensing techniques).

The spatial variability in soil moisture was seen to increase with wetness conditions, at both the catchment and transect scale. Within-field variability was found to be greater than between-field variability. A variation in 
the nugget of the empirial semivariograms from the different transects suggested the influence of micro-topographical features and soil properties on spatial soil moisture variability. Large variability is seen even at very small distances within the transects, making estimations of a correlation length difficult. Topographical features (slope) may enhance spatial structure at distances greater than $30 \mathrm{~m}$ within a transect as evidenced by a sill, however, more measurements should be done to confirm the consistency of this finding.

Temporal stability in soil moisture conditions has been observed in the in situ measurements. One particular transect exhibited the largest rank stability of all the six fields. This transect can be characterized as displaying average values for upslope drainage area, elevation, slope and soil properties, as compared to the other fields in this study. This indicates that if the selection of a representative site is desired for catchment mean soil moisture estimation, sites displaying average characteristics should be considered. However, it was also shown that the spatial characteristics of rainfall influence the spatial variability of soil moisture within the catchment. Differences of soil moisture between two fields increased from less than 1 vol \% to greater than 8 vol \% following the occurrence of a highly spatially variable precipitation event. This highlights the importance of obtaining high spatial-resolution and reliable rainfall measurements even at the small catchment scale. When 
a limited number of soil moisture measurements is considered as catchment representative, the spatial variability of precipitation events should be taken into account.

Comparison of the in situ soil moisture measurements with the ASCAT soil moisture product lead to a correlation coefficient of 0.55 . In general the data agreed well and followed a similar signal, even though both techniques have different spatial resolutions and a different measuring depth $(6 \mathrm{~cm}$ for in situ measurements versus $2-3 \mathrm{~cm}$ for the satellite product). The results showed that there is large potential for satellite data to complement in situ data.

Runoff response was shown to be highly dependent on antecedent soil moisture conditions. Runoff ratios varied by two orders of magnitude with a difference of precipitation input of less than $20 \%$ between two events. The strong influence of initial soil moisture conditions on runoff generation further underlines the importance of antecedent catchment conditions for flood prediction at the catchment scale. In the absence of in situ soil moisture data, satellite data can be a good indicator for catchment conditions. 


\section{${ }_{776} 6$ Acknowledgements}

The study was conducted under the HyMeX program, sponsored by Grants MISTRALS/HyMeX, ANR-2011-BS56-027 FLOODSCALE project and OHMCV. The authors thank the Environmental Remote Sensing Laboratory (École Polytechnique Fédérale de Lausanne) for operating and providing the data from the X-band dual polarization weather radar (MXPol), and MétéoFrance for providing long term precipitation data. Hpiconet data was provided by Gilles Molinié (Precis Mecanique $1000 \mathrm{~cm}^{2}$ rain gauge) and Alexis Berne (OTT Parsivel disdrometer). The authors also thank Brice Boudevillain for assistance with the Hpiconet data and to Henk Pietersen for the microwave link data. In addition, the authors acknowledge the EPLEFPA Olivier de Serres and the municipality of Mirabel for their hospitality and their assistance in the experiments. AJT acknowledges the financial support from The Netherlands Organisation for Scientific Research through Veni Grant 016.111.002. 
Author-produced version of the article published in Journal of Hydrology (2014), vol. 516, p. 330-342 The original publication is available at http://www.sciencedirect.com/ http://dx.doi.org/10.1016/j.jhydrol.2014.01.041 


\section{References}

Albergel, C., C. Ruediger, D. Carrer, J.-C. Calvet, N. Fritz, V. Naemi, Z. Bartalis, and S. Hasenauer (2009), An evaluation of ascat surface soil moisture products with in-situ observations in southwestern france, Hydrology and Earth System Sciences, 13, 115-124.

Albertson, J., and G. Kiely (2000), On the structure of soil moisture time series in the context of land surface models, J. Hydrol., 243, 101-119.

Albertson, J., and N. Montaldo (2003), Temporal dynamics of soil moisture variability: 1. theoretical basis, Water Resour. Res., 39(10), 1274.

Aronica, G., and A. Candela (2004), A regional methodology for deriving flood frequency curves (FFC) in partially gauged catchment with uncertain knowledge of soil moisture conditions, in The International Environmental Modelling and Software Society Conference, Osnabruck, Germany.

Bartalis, Z., W. Wagner, V. Naemi, S. Hasenauer, K. Scipal, H. Bonekamp, J. Figa, and C. Anderson (2007), Initial soil moisture retrievals from the metop-a advanced scatterometer (ASCAT), Geophys. Res. Lett., 34, 1-5.

Borga, M., P. Boscolo, F. Zanon, and M. Sangati (2007), Hydrometeorological analysis of the 29 august 2003 flash flood in the Eastern Italian Alps, J. Hydrometeorol., 8, 1049-1066. 
Brocca, L., R. Morbidelli, F. Melone, and T. Moramarco (2007), Soil moisture spatial variability in experimental areas of central italy, J. Hydrol., 333, $356-373$.

Brocca, L., F. Melone, T. Moramarco, and R. Morbidelli (2009a), Soil moisture temporal stability over experimental areas of central italy, Geoderma, $148(3-4), 364-374$.

Brocca, L., F. Melone, T. Moramarco, and V. Singh (2009b), Assimilation of observed soil moisture data in storm rainfall-runoff modeling, J. Hydraul. Eng., 14(2), 153-165.

Brocca, L., F. Melone, T. Moramarco, and R. Morbidelli (2010), Spatialtemporal variability of soil moisture and its estimation across scales, Water Resour. Res., 46, 2516.

Brocca, L., S. Hasenauer, T. Lacava, F. Melone, T. Moramarco, W. Wagner, W. Dorigo, P. Matgen, J. Martinez-Fernandez, P. Llorens, J. Latron, C. Martin, and M. Bittelli (2011), Soil moisture estimation through ASCAT and AMSR-E sensors: An intercomparison and validation study across Europe, Remote Sens. Environ., 115, 3390-3408.

Brocca, L., T. Tullo, F. Melone, T. Moramarco, and R. Morbidelli (2012), 
Catchment scale soil moisture spatial-temporal variability, J. Hydrol., 422423, $63-75$.

Brocca, L., T. Moramarco, and W. Wagner (2013), A new method for rainfall estimation through soil moisture observations, Geophysical Research Letters, 40, 853-858.

Castillo, V., A. Gómez-Plaza, and M. Martínez-Mena (2003), The role of antecedent soil water content in the runoff response of semiarid catchments: a simulation approach, J. Hydrol., 284(1-4), 114-130.

Chen, Y.-J. (2006), Letter to the editor on "rank stability or temporal stability", Soil Sci. Soc. Am. J., 70(1), 306-306.

Cosh, M., T. Jackson, R. Bindlish, and J. Prueger (2004), Watershed scale temporal and spatial stability of soil moisture and its role in validating satellite estimates, Remote Sens. Environ., 92, 427-435.

De Michele, C., and G. Salvadori (2002), On the derived flood frequency distribution: analytical formulation and the influence of antecedent soil moisture condition, J. Hydrol., 262, 245-258.

Delrieu, G., V. Ducrocq, E. Gaume, J. Nicol, O. Payrastre, E. Yates, P.-E. Kirstetter, H. Andrieu, P.-A. Ayral, C. Bouvier, J.-D. Creutin, M. Livet, S. Anquetin, M. Lang, L. Neppel, C. Obled, J. P. du Châtelet, G.-M. 
Saulnier, A. Walpersdorf, and W. Wobrock (2005), The catastrophic flashflood event of 8-9 september 2002 in the Gard region, France: A first case study for the Cévennes-Vivarais Mediterranean hydrometeorological observatory, J. Hydrometeorol., 6, 34-52.

Drobinski, A., V. Ducrocq, P. Alpert, P. Anagnostou, K. Béranger, M. Borga, I. Braud, A. Chanzy, S. Davolio, G. Delrieu, C. Estournel, N. F. Boubrahmi, J. Font, V. Grubisic, S. Gualdi, B. Ivenean-Picek, C. Kottmeier, V. Kotroni, K. Lagouvardos, P. Lionello, M. C. Llasat, W. Ludwig, C. Lutoff, A. Mariotti, E. Richard, R. Romero, R. Rotunno, O. Roussot, I. Ruin, V. H. Santaner, S. Somot, I. Taupier-Letage, J. Tintore, R. Uijlenhoet, and H. Wernli (2013), HyMeX, a 10-year multidisciplinary program on the Mediterranean water cycle, b. Am. Meteorol. Soc., submitted.

Ducrocq, V., O. Roussot, K. Béranger, I. Braud, A. Chanzy, G. Delrieu, P. Drobinski, C. Estournel, B. Ivenean-Picek, S. Josey, K. Lagouvardos, P. Lionello, M. C. Llasat, W. Ludwig, C. Lutoff, A. Mariotti, A. Montanari, E. Richard, R. Romero, I. Ruin, and S. Somot (2010), HyMeX science plan, Tech. Rep. 2.3.2, Météo-France.

Ducrocq, V., I.Braud, S. Davolio, R. Ferretti, C. Flamant, A. Jansa, N. Kalthoff, E. Richard, I. Taupier-Letage, P.-A. Ayral, S. Belamari, 
A. Berne, M. Borga, B. Boudevillain, O. Bock, J.-L. Boichard, M.-N. Bouin, O. Bousquet, C. Bouvier, J. Chiggiato, D. Cimini, U. Corsmeier, L. Coppola, P. Cocquerez, E. Defer, J. Delanoë, P. Di Girolamo, A. Doerenbecher, P. Drobinski, Y. Dufournet, N. Fourrié, J. J. Gourley, L. Labatut, D. Lambert, J. Le Coz, F. S. Marzano, G. Molinié, A. Montani, G. Nord, M. Nuret, K. Ramage, B. Rison, O. Roussot, F. Said, A. Schwarzenboeck, P. Testor, J. Van Balen, B. Vincendon, M. Aran, and J. Tamayo (2013), HyMeX-SOP1, the field campaign dedicated to heavy precipitation and flash flooding in the northwestern Mediterranean, American Meteorological Society, doi:10.1175/BAMS-D-12-00244.1, in press.

Famiglietti, J. S., J. W. Rudnicki, and M. Rodell (1998), Variability in soil moisture content along a hillslope transect: Rattlesnake hill, Texas, J. Hydrol., 210, 259-281.

Famiglietti, J. S., D. Ryu, A. A. Berg, M. Rodell, and T. J. Jackson (2008), Field observations of soil moisture variability across scales, Water Resour. Res., 44, 1423.

Figa-Saldaña, J., J. J. W. Wilson, E. Attema, R. Gelsthorpe, M. R. Drinkwater, and A. Stoffelen (2002), The advanced scatterometer (ASCAT) on the meteorological operational (MetOp) platform: A follow on European wind scatterometers, Can. J. Remote Sens., 28, 404-412. 
Gaume, E., M. Livet, M. Desbordes, and J.-P. Villeneuve (2004), Hydrological analysis of the river Aude, France, flash flood on 12 and 13 november 1999, J. Hydrol., 286, 135-154.

Gaume, E., V. Bain, P. Bernardara, O. Newinger, M. Barbuc, A. Bateman, L. Blakškovičová, G. Blöschl, M. Borga, A. Dumitrescu, I. Daliakopoulos, J. Garcia, A. Irimescu, S. Kohnova, A. Koutroulis, L. Marchi, S. Matreata, V. Medina, E. Preciso, D. Sempere-Torres, G. Stancalie, J. Szolgay, I. Tsanis, D. Velasco, and A. Viglione (2009), A compilation of data on European flash floods, J. Hydrol., 367, 70-78.

Goovaerts, P. (1997), Geostatistics for Natural Resources Evaluation, no. xiv + 483 pp in Applied Geostistics Series, Oxford University Press.

Kerr, Y. (2007), Soil moisture from space: Where are we?, Hydrogeol. J., $15(1), 117-120$.

Kerr, Y., P. Waldteufel, J.-P. Wigneron, S. Delwart, F. Cabot, J. Boutin, M.J. Escorihuela, J. Font, N. Reul, C. Gruhier, S. Enache Juglea, M. Drinkwater, A. Hahne, M. Martin-Neira, and S. Mecklenburg (2010), The SMOS mission: New tool for monitoring key elements of the global water cycle, P IEEE, 98, 666-687.

Le Coz, J., B. Renard, L. Bonnifait, F. Branger, and R. Le Boursicaud (2013), 
Combining hydraulic knowledge and uncertain gaugings in the estimation of hydrometric rating curves: a Bayesian approach, J. Hydrol., 509, 573587, doi:http://dx.doi.org/10.1016/j.jhydrol.2013.11016.

Martínez, G., Y. Pachepsky, and H. Vereecken (2013), Temporal stability of soil water content as affected by climate and soil hydraulic properties: A simulation study, Hydrol. Process., Published online, doi:10.1002/hyp.9737.

Massari, C., L. Brocca, S. Barbetta, C. Papathanasiou, M. Mimikou, and T. Mor (2013), Using globally available soil moisture indicators for flood modelling in Mediterranean catchments, Hyrol. Earth Sys. Sci. Discuss., $10,10,997-11,033$.

Naemi, V., K. Scipal, Z. Bartalis, S. Hasenauer, and W. Wagner (2009), An improved soil moisture retrieval algorithm for ers and metop scatterometer observations, IEEE Transactions on Geoscience and Remote Sensing, 47(7), 1999-2013.

Norbiato, D., M. Borga, R. Merz, G. Blöschl, and A. Carton (2009), Controls on event runoff coefficients in the eastern Italian Alps, J. Hydrol., 375, $312-325$.

Owe, M., R. de Jeu, and T. Holmes (2008), Multisensor historical climatology 
of satellite-derived global land surface moisture, J. Geophys. Res., 113, 117.

Ponce, V., and R. Hawkins (1996), Runoff curve number: Has it reached maturity?, J. Hydrol. Eng., 1(1), 11-19.

Rosenbaum, U., H. R. Bogena, M. Herbst, J. A. Huisman, T. J. Peterson, A. Weuthen, A. W. Western, and H. Vereecken (2012), Seasonal and event dynamics of soil moisture patterns at the small catchment scale, Water Resour. Res., 48, W10544.

Salkind, N. J. (2010), Encyclopedia of Research Design, SAGE Publications, Inc.

Sangati, M., M. Borga, D. Rabuffetti, and R. Bechini (2009), Influence of rainfall and soil properties spatial aggreggation on extreme flood response modelling: An evaluation based on the Sesia river basin, North Western Italy, Adv. Water Resour., 32, 1090-1106.

Tallaksen, L. M., and H. A. Van Lanen (2004), Hydrological Drought Processes and Estimation Methods for Streamflow and Groundwater, Developments in Water Science, Elsevier.

Teuling, A., R. Uijlenhoet, F. Hupet, E. Van Loon, and P. Troch (2006), Esti- 
mating spatial mean root-zone soil moisture from point-scale observations, Hydrol. Earth Sys. Sci., 10, 755-767.

Teuling, A. J., and P. A. Troch (2005), Improved understanding of soil moisture variability dynamics, Geophys. Res. Lett., 32(5)(5), L05404, doi: 10.1029/2004GL021935.

Tramblay, Y., C. Bouvier, C. Martin, J.-F. Didon-Lescot, D. Todorovik, and J.-M. Domergue (2010), Assessment of initial soil moisture conditions for event-based rainfall-runoff modelling, J. Hydrol., 38\%, 176-187.

Vachaud, G., A. Passerat de Silans, P. Balabanis, and M. Vauclin (1985), Temporal stability of spatially measured soil water probability density function, Soil Sci. Soc. Am. J., 49, 822-828.

Vanderlinden, K., H. Vereecken, H. Hardelauf, M. Herbst, G. Martinez, M. Cosh, and Y. Pachepsky (2012), Temporal stability of soil water contents: A review of data and analyses, Vadose Zone J., 11(4).

Wagner, W., G. Lemoine, and H. Rott (1999), A method for estimating soil moisture from ers scatterometer and soil data, Remote Sensing of the Environment, 70(2), 191-207.

Wagner, W., J. Figa, C. Albergel, L. Brocca, S. Hahn, S. Hasenauer, and W. Dorigo (2013), Operations, challenges and prospects of satellite-based 
Western, A. W., G. Blöschl, and R. B. Grayson (1998), Geostatistical characterisation of soil moisture patterns in the Tarrawarra catchment, J. Hydrol., 205, 20-37.

Western, A. W., S.-L. Zhou, R. B. Grayson, T. A. McMahon, G. Blöschl, and D. J. Wilson (2004), Spatial correlation of soil moisture in small catchments and its relationship to dominant spatial hydrological processes, J. Hydrol., 286, 113-134. 
Table 1: Summary of the transect mean in situ volumetric soil moisture (vol \%) over the fall 2012 SOP, along with limited topographical and soil properties, as well as land use for each of the transects measured. Initial, final and maximum mean in situ volumetric soil moisture is shown for each of the transects as Initial $\theta_{v}$, Final $\theta_{v}$ and $\operatorname{Max} \theta_{v}$, respectively.

\begin{tabular}{|c|c|c|c|c|c|c|c|c|c|}
\hline Transect & $\begin{array}{l}\text { Slope } \\
(-)\end{array}$ & $\begin{array}{l}\text { Porosity } \\
(-)\end{array}$ & $\begin{array}{l}\% \\
\text { Sand }\end{array}$ & $\begin{array}{l}\% \\
\text { Silt }\end{array}$ & $\begin{array}{l}\% \\
\text { Clay }\end{array}$ & $\begin{array}{l}\text { Initial } \\
\theta_{v}\end{array}$ & $\begin{array}{l}\text { Final } \\
\theta_{v}\end{array}$ & $\begin{array}{l}\operatorname{Max} \\
\theta_{v}\end{array}$ & $\begin{array}{l}\text { Land } \\
\text { Use }\end{array}$ \\
\hline $\mathrm{A}$ & 0.006 & 0.55 & 43 & 12 & 45 & 12.57 & 30.68 & 36.69 & pasture \\
\hline B & 0.133 & 0.53 & 47 & 18 & 36 & 13.50 & 27.59 & 36.13 & pasture \\
\hline $\mathrm{C}$ & 0.059 & 0.66 & 35 & 19 & 46 & 16.09 & 35.34 & 38.64 & grassland \\
\hline $\mathrm{D}$ & 0.120 & 0.59 & 44 & 20 & 36 & 14.68 & 33.63 & 36.52 & grassland \\
\hline $\mathrm{E}$ & 0.130 & 0.59 & 42 & 16 & 42 & 14.23 & 32.42 & 42.74 & grassland \\
\hline $\mathrm{F}$ & 0.230 & 0.62 & 46 & 17 & 38 & 14.51 & 31.47 & 43.22 & grassland \\
\hline
\end{tabular}


Table 2: Comparison of five precipitation events during the fall 2012 SOP. $P$ Sum represents the total accumulated hourly precipitation as measured by the disdrometers over the event period. Standard deviation and coefficient of variation, denoted by $\operatorname{sd}(P)$ and $\operatorname{CV}(P)$, of the precipitation data measured at the Le Pradel and Mirabel locations. $Q_{\text {event }}$ Sum represents the flow discharged over the event period, with pre-event discharge denoted as $Q_{i}$. The runoff ratio $(\mathrm{RR})$ is calculated by dividing $Q_{\text {event }}$ Sum by $P$ Sum. The volumetric soil moisture prior to the precipitation event for in situ and satellite sources are represented by $\theta_{i}$ and ASCAT $\theta_{i}$, respectively. The post-event in situ volumetric soil moisture data is denoted by $\theta_{i+1}$. Dates include: 23-28 September (Event \#1), 19-22 October (Event \#2), 9-17 November (Event \#3), 22 November-1 December (Event \#4), and 23-31 October (Event \#5).

\begin{tabular}{|c|c|c|c|c|c|c|}
\hline Characteristic & Units & Event \#1 & Event \#2 & Event \#3 & Event \#4 & Event \#5 \\
\hline$P$ Sum & $\mathrm{mm}$ & 49 & 8 & 63 & 45 & 47 \\
\hline $\operatorname{sd}(P)$ & $\mathrm{mm}$ & 0.04 & 0.002 & 0.002 & 0.005 & 0.006 \\
\hline $\mathrm{CV}(P)$ & - & 0.13 & 0.03 & 0.005 & 0.02 & 0.02 \\
\hline$Q_{\text {event }}$ Sum & $\mathrm{mm}$ & 0.17 & 0.0079 & 21.17 & 18.85 & 0.39 \\
\hline$Q_{i}$ & $1 s^{-1}$ & 0.44 & 0.78 & 14.3 & 13.1 & 0.97 \\
\hline $\mathrm{RR}$ & - & 0.0035 & 0.0012 & 0.29 & 0.38 & 0.011 \\
\hline$\theta_{i}$ & vol $\%$ & 14 & 23 & - & - & - \\
\hline$\theta_{i+1}$ & vol $\%$ & 27 & 31 & 34 & 39 & - \\
\hline $\operatorname{ASCAT} \theta_{i}$ & vol $\%$ & 16 & 23 & 22 & 24 & 27 \\
\hline
\end{tabular}


Table 3: Influence of spatial variability of precipitation on volumetric soil moisture variability among Transect A and E during Event \#1. Hourly accumulated precipitation amounts from the rain gauge (Gauge), disdrometer (DSD), radar (Radar) and microwave link (Link) are shown. $P$ calc denotes the precipitation estimate using the differences of in situ soil moisture measurements from the $23^{\text {rd }}(2309)$ and $24^{\text {th }}$ (2409) September 2012 over the top $6 \mathrm{~cm}$.

\begin{tabular}{llllllllll}
\hline & \multicolumn{3}{c}{ Soil Moisture (vol \%) } & \multicolumn{4}{c}{ Precipitation $(\mathrm{mm})$} & \multicolumn{2}{l}{ Max Int $\left(\mathrm{mm} 10 \mathrm{~min}^{-1}\right)$} \\
Transect & 2309 & 2409 & Diff & $\begin{array}{l}P \\
\text { calc }\end{array}$ & DSD & Gauge Radar & Link & P int \\
& & & & calc & & & \\
\hline A & 14.8 & 32.0 & 17.2 & 10 & 24 & 30 & 23 & - & 34 \\
E & 14.2 & 23.9 & 9.7 & 6 & 15 & 18 & 11 & - & 21 \\
\hline \multicolumn{2}{l}{ Catchment } & & & & 20 & 24 & 17 & 19 & \\
\hline
\end{tabular}




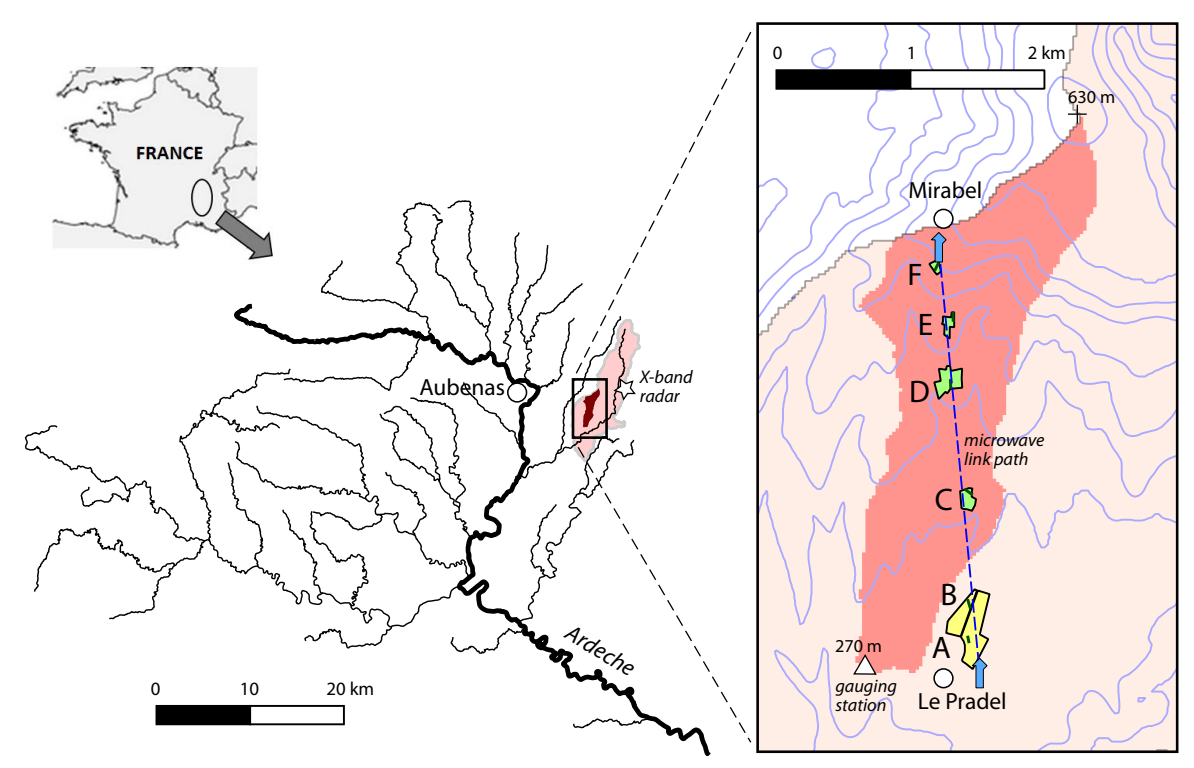

Figure 1: Map of the Ardèche catchment and the Gazel sub-catchment, including measurements being done over the fall 2012 SOP1 in the Gazel catchment. Blue arrows indicate the locations of the disdrometer, rain gauges, as well as the transmitting and receiving ends of the microwave link. Circles represent the villages of Mirabel and Le Pradel. Letters show the locations of the $50 \mathrm{~m}$ transects measured throughout the SOP1, which are found in line with the microwave link path (dotted line). The rain gauge operated by Méteo-France is located within $200 \mathrm{~m}$ of the lower blue arrow at Le Pradel. 


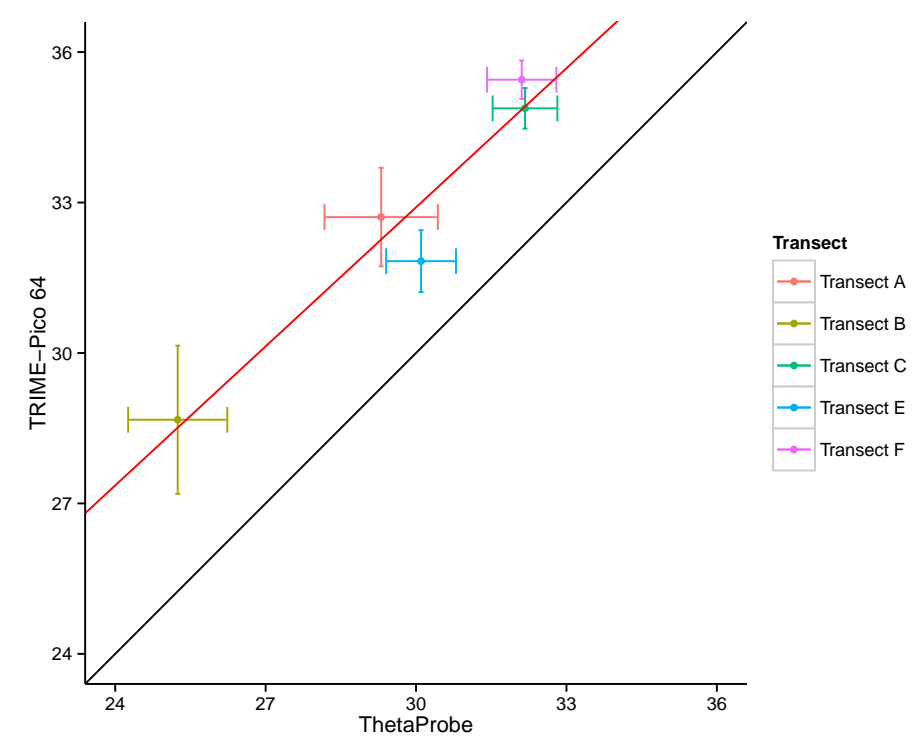

Figure 2: Comparison of volumetric soil moisture transect means on the $14^{\text {th }}$ November 2012 with the ThetaProbe (rod length $6 \mathrm{~cm}$ ) and TRIME-Pico 64 (rod length $16 \mathrm{~cm}$ ). Error bar lengths based on the standard error $S E$ of the transect means. 


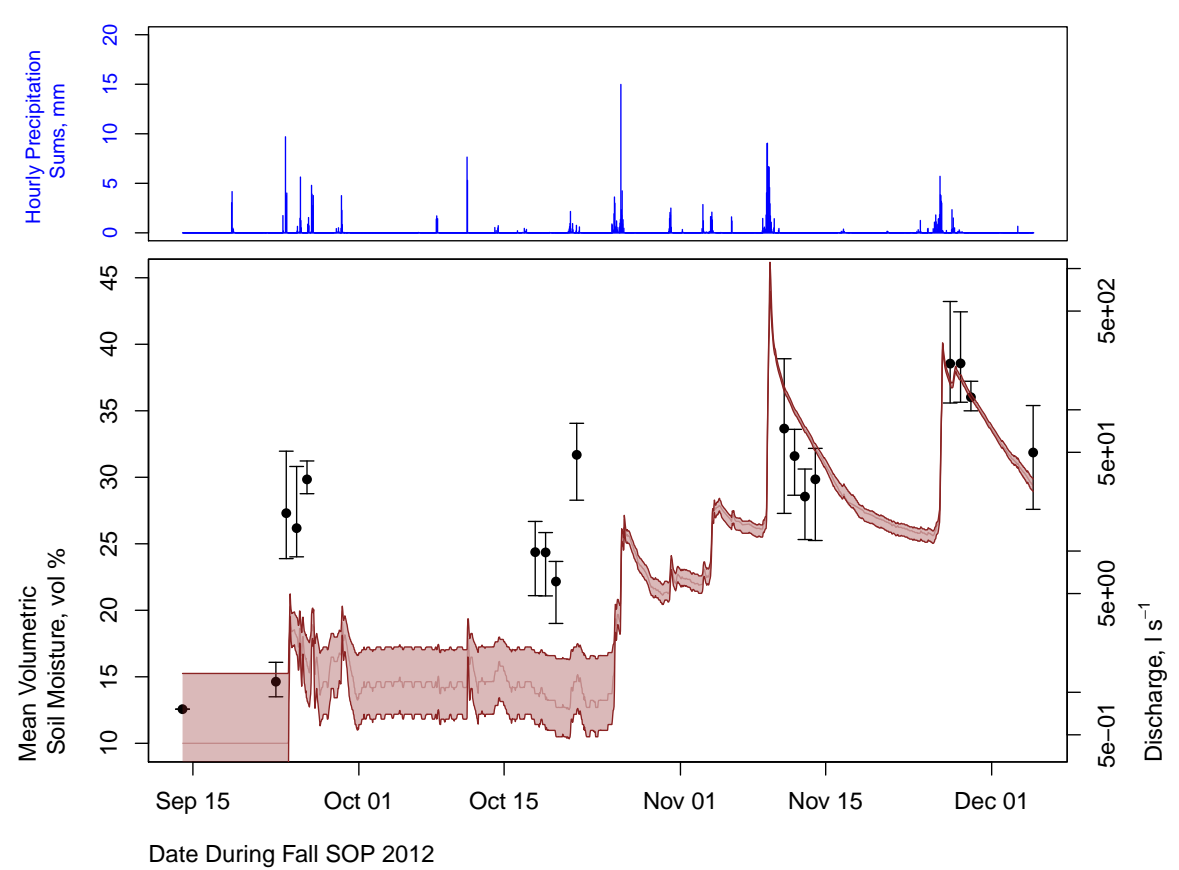

Figure 3: Upper panel: Hourly accumulations for precipitation in $\mathrm{mm}$ as estimated by averaging the two disdrometers located in the upper and lower part of the catchment. Lower panel: Mean volumetric in situ soil moisture (vol \%) at the catchment scale throughout the SOP. The brown curve shows the discharge in $1 \mathrm{~s}^{-1}$, with catchment mean volumetric in situ soil moisture measurements (black dots) along with \pm standard deviation as error bars. Four precipitation events are seen on the following dates: 23-28 September (Event \#1), 19-22 October (Event \#2), 9-17 November (Event \#3), and 22 November-1 December (Event \#4). 


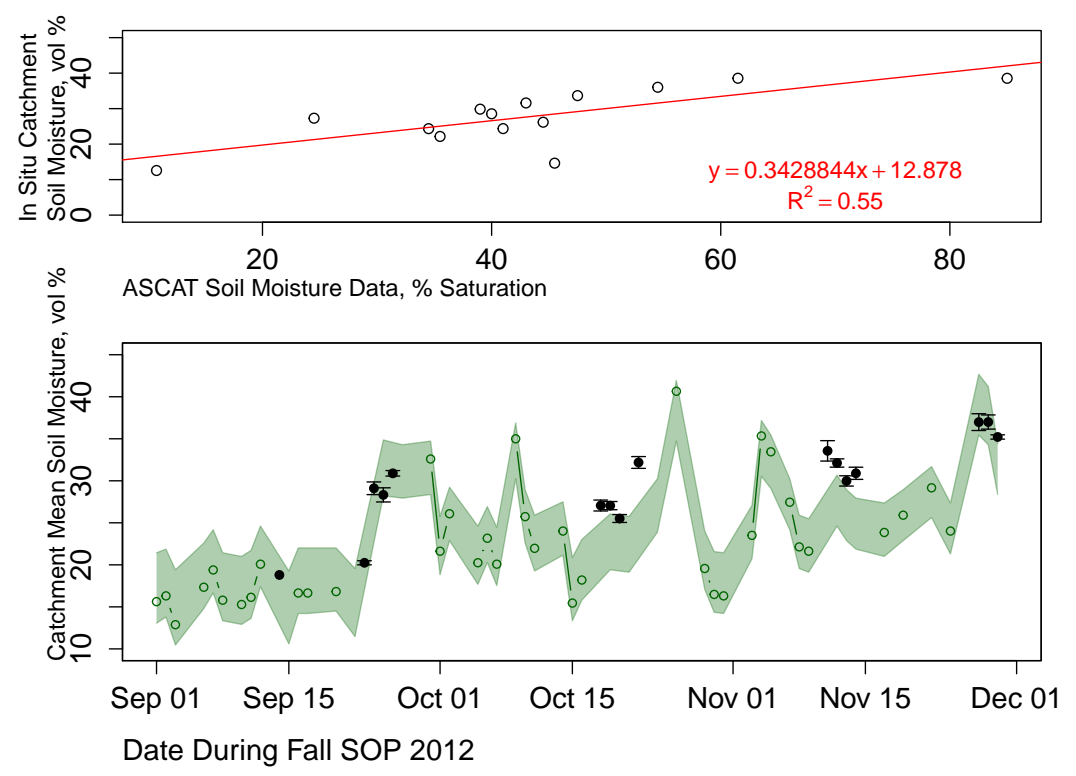

Figure 4: Upper panel: Linear regression of ASCAT satellite observations with in situ volumetric soil moisture measurements (daily catchment means). Lower panel: Time series of ASCAT volumetric soil moisture (open circles) as derived by a linear regression with in situ catchment mean measurements. The error bands (green band) represent the measurement error for the rescaled ASCAT (Figa-Saldaña et al., 2002) data. Catchment mean in situ volumetric soil moisture measurements (filled circles) with error bars based on \pm the standard deviation are also shown. 


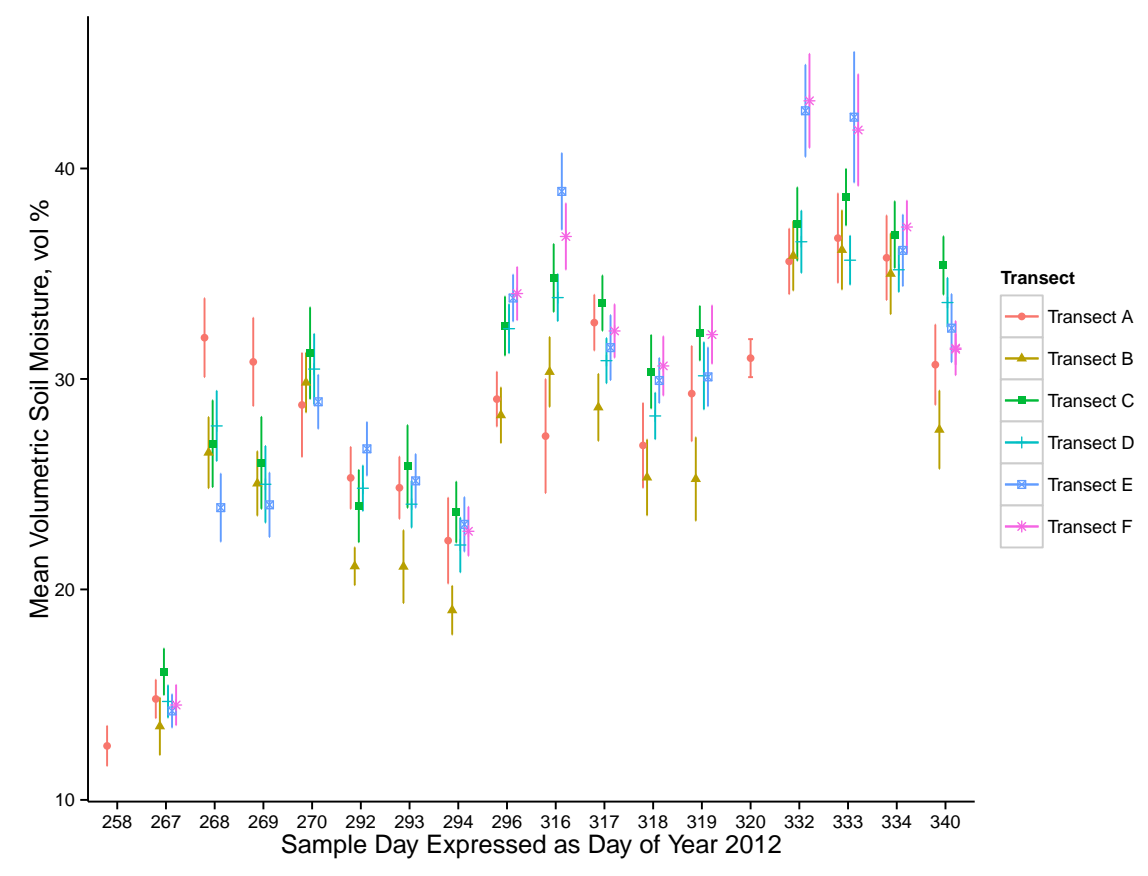

Figure 5: Transect mean volumetric in situ soil moisture for all measurement days as represented by Day of Year (DOY). Error bars indicate 2 times \pm $S E$. 


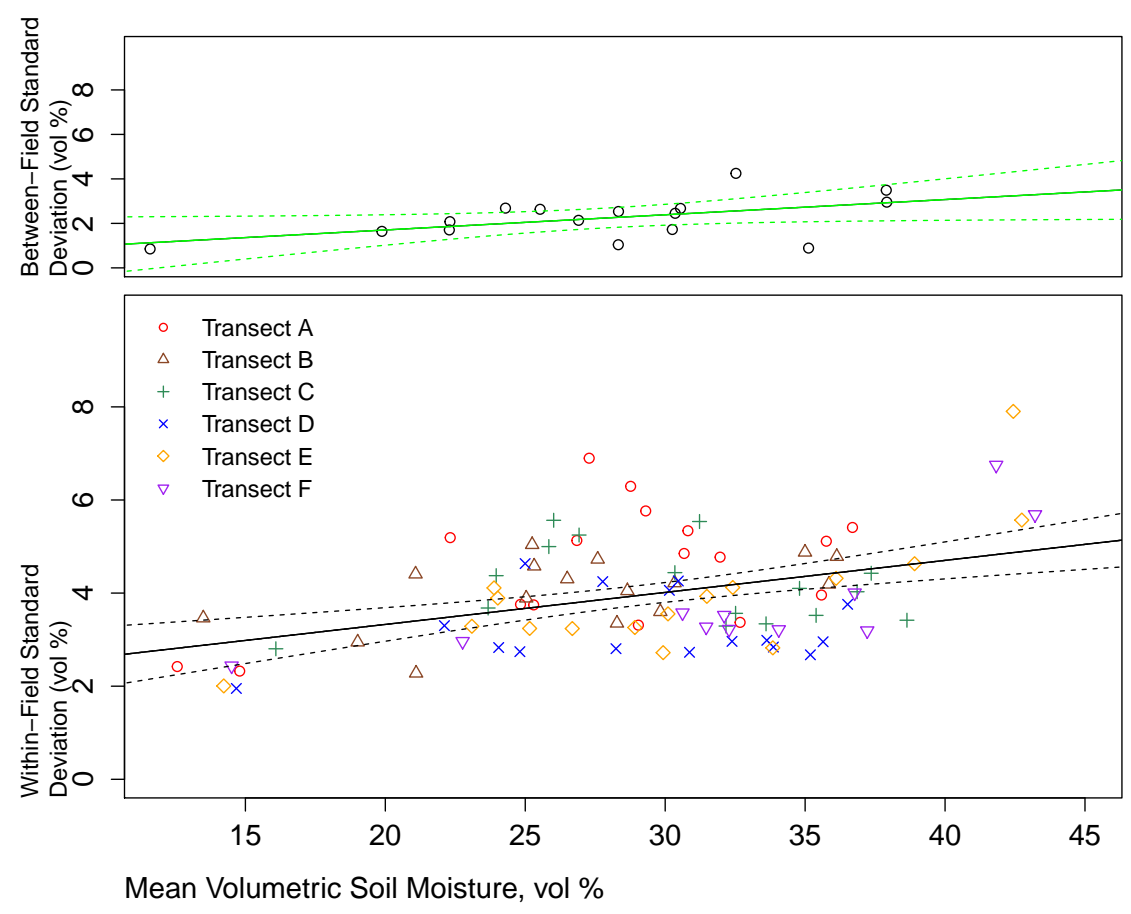

Figure 6: Relationship between mean volumetric in situ soil moisture (vol $\%$ ) and standard deviation at varying soil moisture conditions. Dotted lines represent a linear fit of the data and solid lines denote the $95 \%$ confidence intervals. Upper panel: within-field variability. Lower panel: between-field variability. 

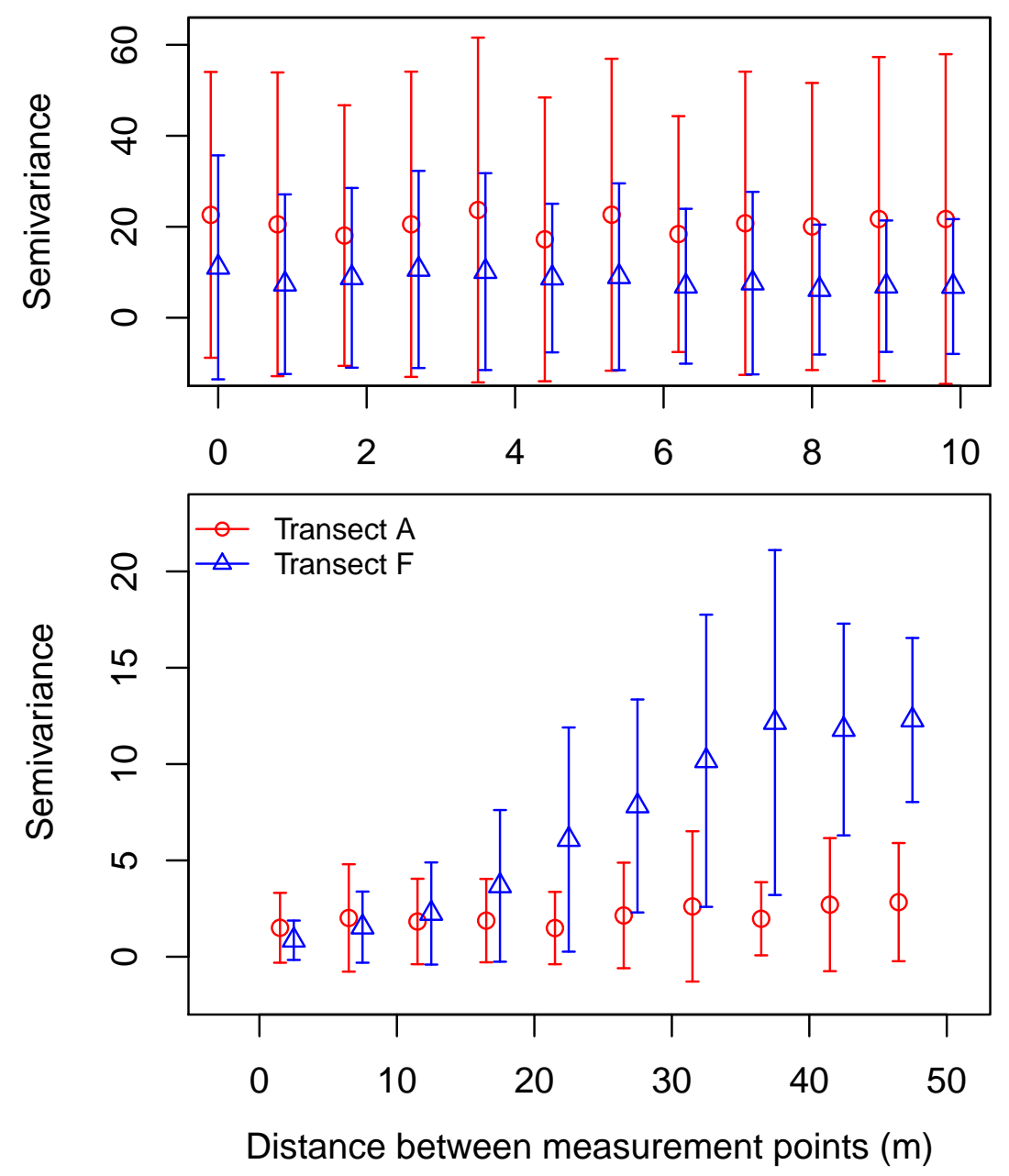

Figure 7: Semi-variogram for Transects A (red circles) and F (blue triangles) with \pm standard deviation as error bars. Upper panel: based on a single measurement day in Transect $\mathrm{A}$ and $\mathrm{F}$ of 101 randomly spaced intervals, with distances ranging from $1 \mathrm{~cm}$ to $2.8 \mathrm{~m}$. A lack of spatial structure at scales smaller than $10 \mathrm{~m}$ is seen here. Lower panel: based on all volumetric soil moisture measurement points done during the observation period at a $2 \mathrm{~m}$ interval spacing in Transect $\mathrm{A}$ and $\mathrm{F}$. The semivariance is seen to be lower here due to averaging out over all measurement days. A clear spatial structure is seen on the average soil moisture conditions for Transect F. 


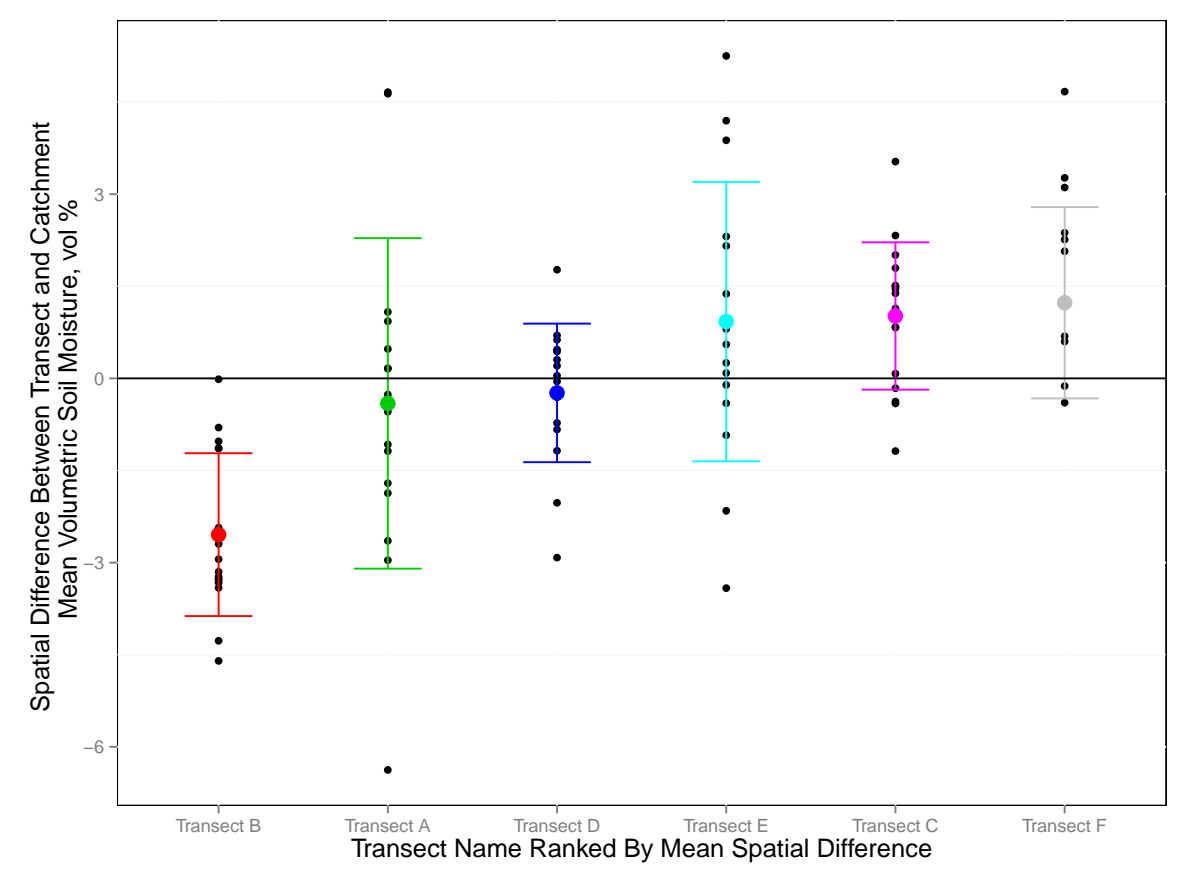

Figure 8: Rank stability plot for the different transect volumetric soil moisture means showing Transect D to be the most temporal stable transect. Black points indicate the spatial difference for each measurement day, the coloured points represent the mean over all measurement days. Error bars correspond to \pm 2 times the standard deviation of the spatial differences. 


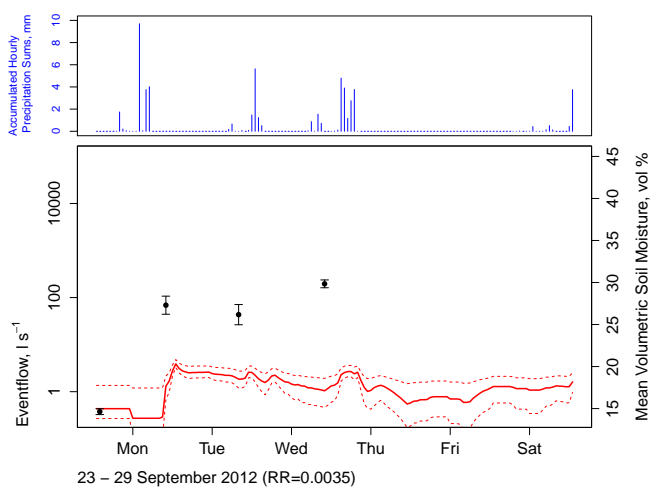

(a) Event \#1

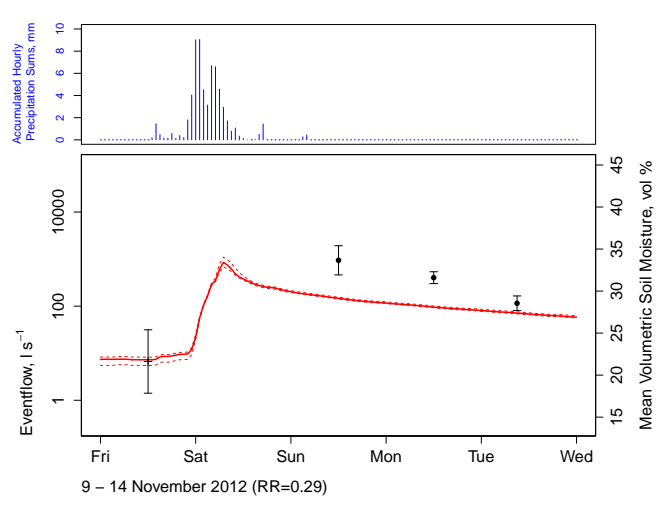

(c) Event \#3

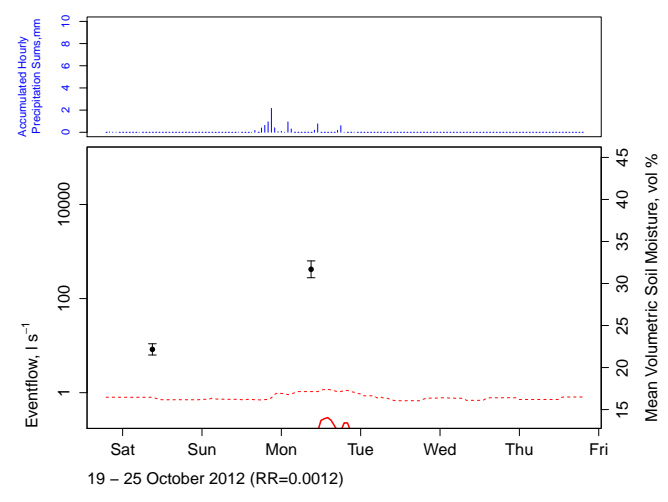

(b) Event \#2

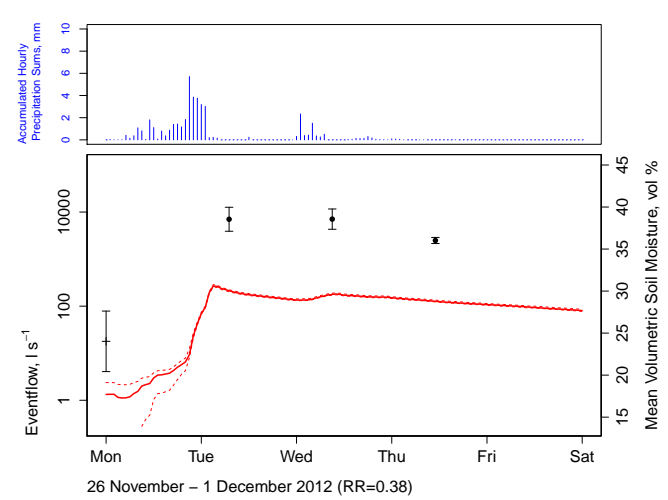

(d) Event \#4

Figure 9: Influence of antecedent soil moisture conditions and precipitation on catchment response during four storm events are shown. Upper panels show hourly precipitation sums in mm as measured by an average of the two disdrometers located in the lower and upper part of the catchment. The lower panels display event flow (baseflow removed) plotted on a log scale as $1 \mathrm{~s}^{-1}$ as a solid red line. Dotted lines indicate the maximum and minimum limits of the discharge based on the error of the stage-discharge curve. The catchment mean volumetric soil moisture is shown in vol $\%$ as in situ data (filled circles) and ASCAT data (crosses). RR denotes the runoff ratio. 


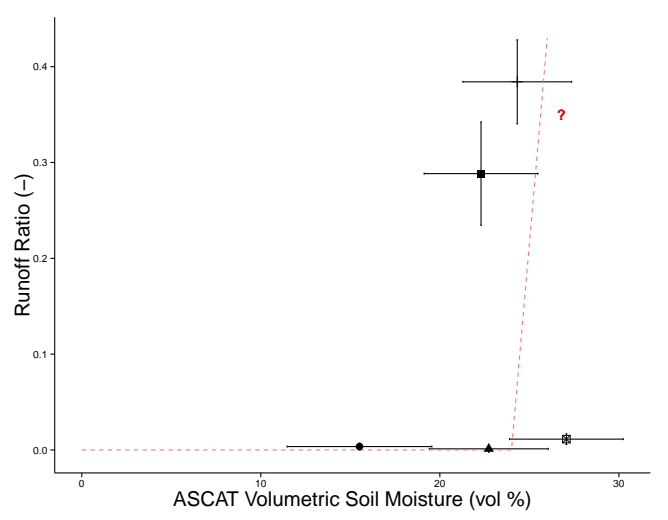

(a) Runoff ratio

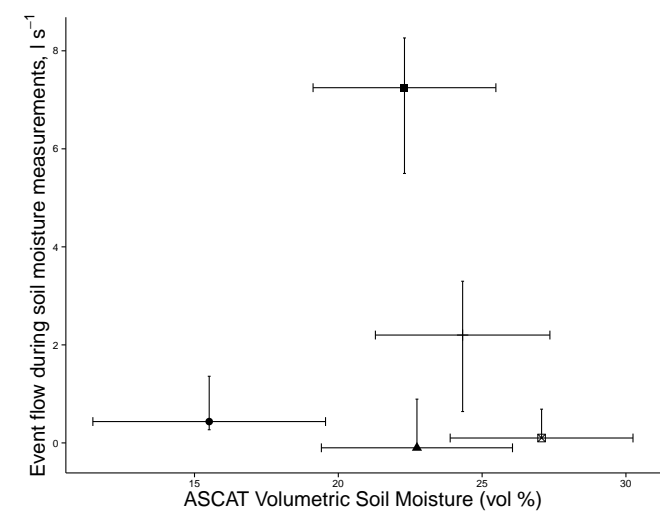

(b) Event flow rate.

Figure 10: Relationship between runoff ratio (a) and event flow rate in $1 \mathrm{~s}^{-1}$ (b) with initial soil moisture content (source: ASCAT) for five precipitation events during the fall 2012. The different events are represented by the following symbols: diamonds (Event \#1, 23-28 September), solid squares (Event \#2, 19-22 October), triangles (Event \#3, 9-17 November), no symbols (Event \#4, 22 November-1 December), and hollow squares (Event \#5, 23-31 October). 